\title{
ALTERATIONS IN THE H-REFLEX IN THE PARAPLEGIC INDUCED BY BLADDER DISTENTION ${ }^{1}$
}

\author{
By Robert W. Porter, M.D., Ph.D. and Martin Krell, M.D. \\ Surgical and Spinal Cord Injury Services, Veterans Administration Hospital, Long Beach, \\ and the Neurosurgical Division, College of Medicine, University of California, Irvine
}

Abstract. This study has evaluated the changes in the characteristics of the H-reflex induced by distention of the urinary bladder in patients with complete lesions of the spinal cord. These findings were compared to induced changes in the systolic blood pressure and some degree of correlation was noted.

IT is well recognised that distention of the urinary bladder can exert a significant influence on the state of both somatic and autonomic reflex activity in spinal man. Although the mode of action of this stimulus has not been fully delineated, it is of some clinical importance since it may intensify muscular spasticity and autonomic hyperreflexia. This study was undertaken to further explore this relationship utilising the $\mathrm{H}$-wave as a measure of segmental reflex activity. When appropriate, the effect of bladder distention on arterial blood pressure was also measured and an attempt made to correlate these observations with the $\mathrm{H}$-wave findings.

\section{Methods}

Experiments were performed on 35 male volunteers ranging in age from 22 to 60 who had sustained injury to their spinal cord. The interval between injury and experimental testing varied from 5 weeks to I8 years. All patients had sustained functionally complete transverse lesions of their spinal cords as determined by serial neurologic examinations.

The basic techniques utilised to record the $\mathrm{H}$-wave reflex were similar to those previously reported (Ishikawa et al., 1965). Recording electrodes were placed several centimetres apart over the soleus muscle and the ground electrode attached above the ankle. The active stimulating electrode was placed in the popliteal fossa at a point where the maximum $\mathrm{H}$-wave could be obtained and the indifferent electrode was placed on the anterior surface of the thigh. The electrical stimulus consisted of a square-wave pulse of 0.5 millisecond duration. This was generated by a Grass $\mathrm{S}_{4}$ stimulator and delivered at a frequency of one every 5 seconds through a stimulus isolation unit. The intensity selected for each patient was that which produced an $\mathrm{H}$-wave with an amplitude of approximately 50 per cent of the maximum $\mathrm{H}$-wave possible for that patient. The stimulus intensity was observed with a current monitor and any significant variation was considered reason to terminate the recording session. Electromyographic potentials were amplified (Grass P5-I I amplifier), observed on an oscilloscope (Tetronix 502) and in early experiments summated on a computer of average transients (Mmematron 400). In later experiments these potentials were recorded on a magnetic tape recorder (Honeywell 7600) and subsequently averaged on an analog-digital

Reprint requests to: Robert W. Porter, M.D., Ph.D., Veterans Administration Hospital 590I East Seventh Street, Long Beach, California 90822, U.S.A.

${ }^{1}$ Supported in part by donations from the California Chapter of the Paralyzed Veterans Association and the Veterans Assistance League. 
computer (PDP-I2) and displayed on an incremental plotter (Houston Complot). Twenty-five successive $\mathrm{H}$-wave responses were averaged for each observation point.

Each patient in this study alteady had an indwelling urethral catheter in place for the treatment of his neurogenic bladder. After first emptying the bladder, the catheter was connected to a manometer for subsequent observations of the intravesical pressure. Patients were given 20 ounces of water to drink and the bladder was allowed to gradually distend with urine. Measurements of the H-wave, bladder pressure (manual sphygomomometer) and pulse rate were made with the bladder empty and then every Io minutes for a total period of 40 minutes. The bladder was then emptied and one additional series of measurements made 10 minutes thereafter.

The subjects in these experiments were divided into three groups. Group I consisted of 29 individuals whose spinal cord dysfunction was of at least 6 months' duration. The level of injury in this group ranged from $\mathrm{C}_{5}$ to Tro. The experiments in this group were performed as described above. Group II consisted of five individuals from Group I who had complete lesions between $\mathrm{TI}_{\mathrm{I}}$ and $\mathrm{T}_{5}$. In these patients the results of the $\mathrm{H}$-wave examinations performed as subjects in Group I experiments were compared with a second series of $\mathrm{H}$-wave results observed during more rapid filling of the bladder. This was accomplished during routine cystometrographic study performed for clinical indications. Such studies were done by the instillation of sterile fluid into the empty bladder through an indwelling catheter at a rate of $0.25 \mathrm{cc}$ per minute. H-wave and blood pressure measurements were made every 3 minutes for a total of 9 minutes. Following this the bladder was emptied and an additional measurement made after 3 minutes. Group III consisted of six additional patients whose spinal cord injury was of recent origin. Each of the six patients was serially examined on three occasions: 5 to 7 , I I to 13 and I 7 to I9 weeks after injury. The methods used in measuring the $\mathrm{H}$-wave response and for distending the bladder were the same as in Group I. All patients in this group had complete spinal cord injury levels between $\mathrm{TI}$ and T5.

Informed consent was obtained from each volunteer for this study. Only those patients for whom it had been previously demonstrated that clamping of the catheter for a period of $\mathrm{I}$ hour during bladder training had no detrimental effect on the patient's well being were used. Additionally all patients were constantly observed for symptoms of autonomic dysreflexia but none were encountered.

\section{Results}

Group I

In all 29 patients there was a significant relationship between bladder pressure and the amplitude of the $\mathrm{H}$-wave. In 24 of these subjects bladder distention was accompanied by an increased $\mathrm{H}$-wave amplitude although the maximum response in the majority of these experiments did not occur at the time of maximum intravesical pressure, but at some earlier time. Figure I represents an example of the change in $\mathrm{H}$-wave amplitude which occurred during increasing bladder pressure measured at Io-minute intervals. It can be noted that the greatest effect occurred at the 30-minute observation point. A further increase in the bladder pressure was associated with a decrease in the amplitude of the $\mathrm{H}$-wave toward the control level. In the remaining five subjects a decrease in the $\mathrm{H}$-wave amplitude was observed during the entire period of bladder distention. These data were further analysed 


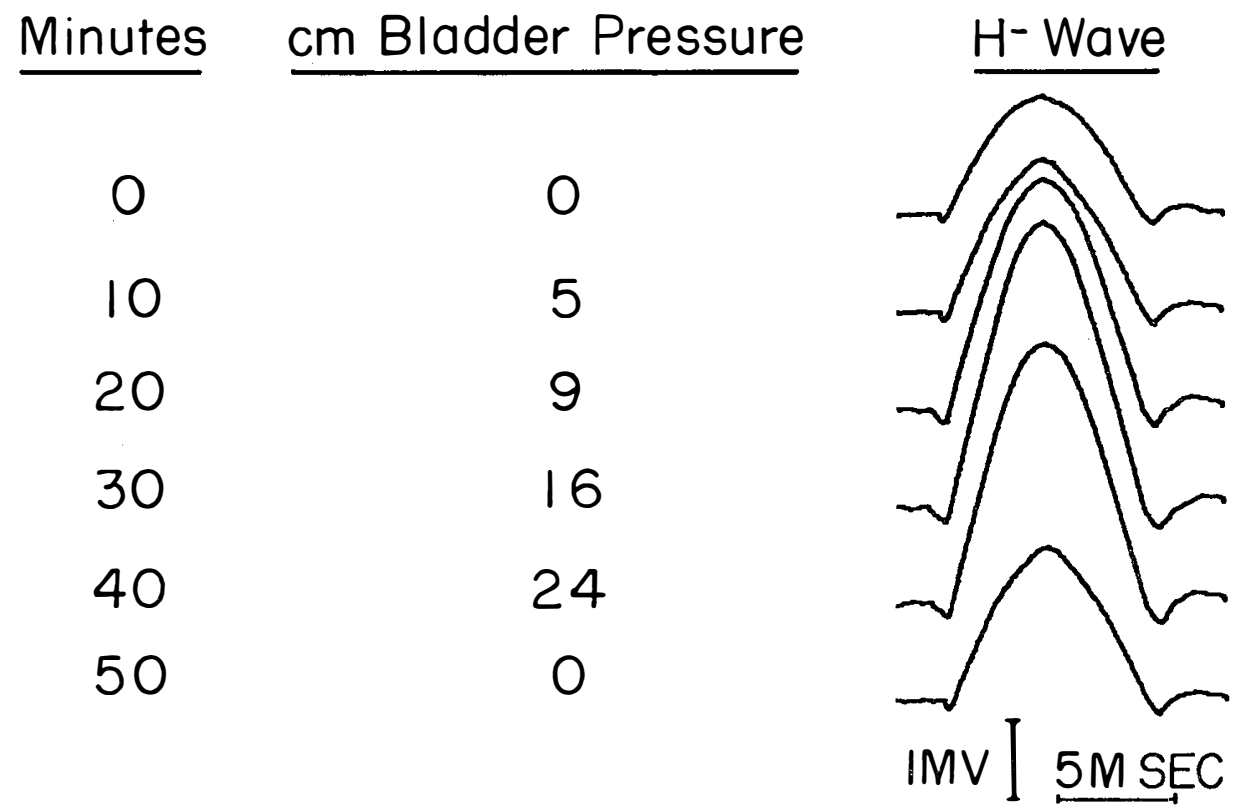

FIG. I

An example of increasing $\mathrm{H}$-wave amplitude with bladder distention in a patient with a functionally complete lesion at T6. The maximum $\mathrm{H}$-wave change is noted at the 30minute observation interval when the bladder pressure is $14 \mathrm{~cm}$. Increasing bladder pressure beyond this point is associated with a return of the $\mathrm{H}$-wave amplitude toward the control value.

according to the level of spinal cord injury and the characteristics of bladder function.

Level of Spinal Injury. The 24 cases described above which showed a positive $\mathrm{H}$-wave response were divided into three subgroups of eight cases each according to the level of spinal cord injury. Group IA consisted of those patients with spinal cord levels between $\mathrm{C}_{5}$ and C8; Group IB those between TI and T5; and Group IC the remaining eight cases with injuries between T6 and Tro. The H-wave response to increasing bladder pressure for each group is shown in Figure 2. It can be noted that in Group IA the maximum increase in H-wave amplitude was seen at the time of maximum bladder pressure. In Group IB, however, the maximum $\mathrm{H}$-wave response occurred at the first Io-minute observation when the bladder pressure was relatively low. In Group IC the maximum $\mathrm{H}$-wave response was noted at the 30-minute interval but was diminished toward the control level at the 40-minute observation point when bladder pressure was at a maximum. The average values for the maximum $\mathrm{H}$-wave change noted and the bladder pressure at which that value was observed as well as the final bladder pressures and volumes are tabulated for each group in Table $\mathrm{I}^{1}$

1 The maximum $\mathrm{H}$-wave change for each group was compared using the t-test and the difference was found to be highly significant between Group IA and Group IB ( $P$ value $<0.0 I$ ). The difference between Groups IB and IC was significant at the 0.05 level while the difference between Group IA and Group IC was not significant ( $P$ value $>0.05$ ). Differences between bladder pressures at which maximum $\mathrm{H}$-wave responses occurred were also compared. Those between Groups IA and IB and between IB and IC were significant at the 0.0 I level. The difference between IA and IC was less significant $(\mathrm{P}$ value $<0.05)$. 


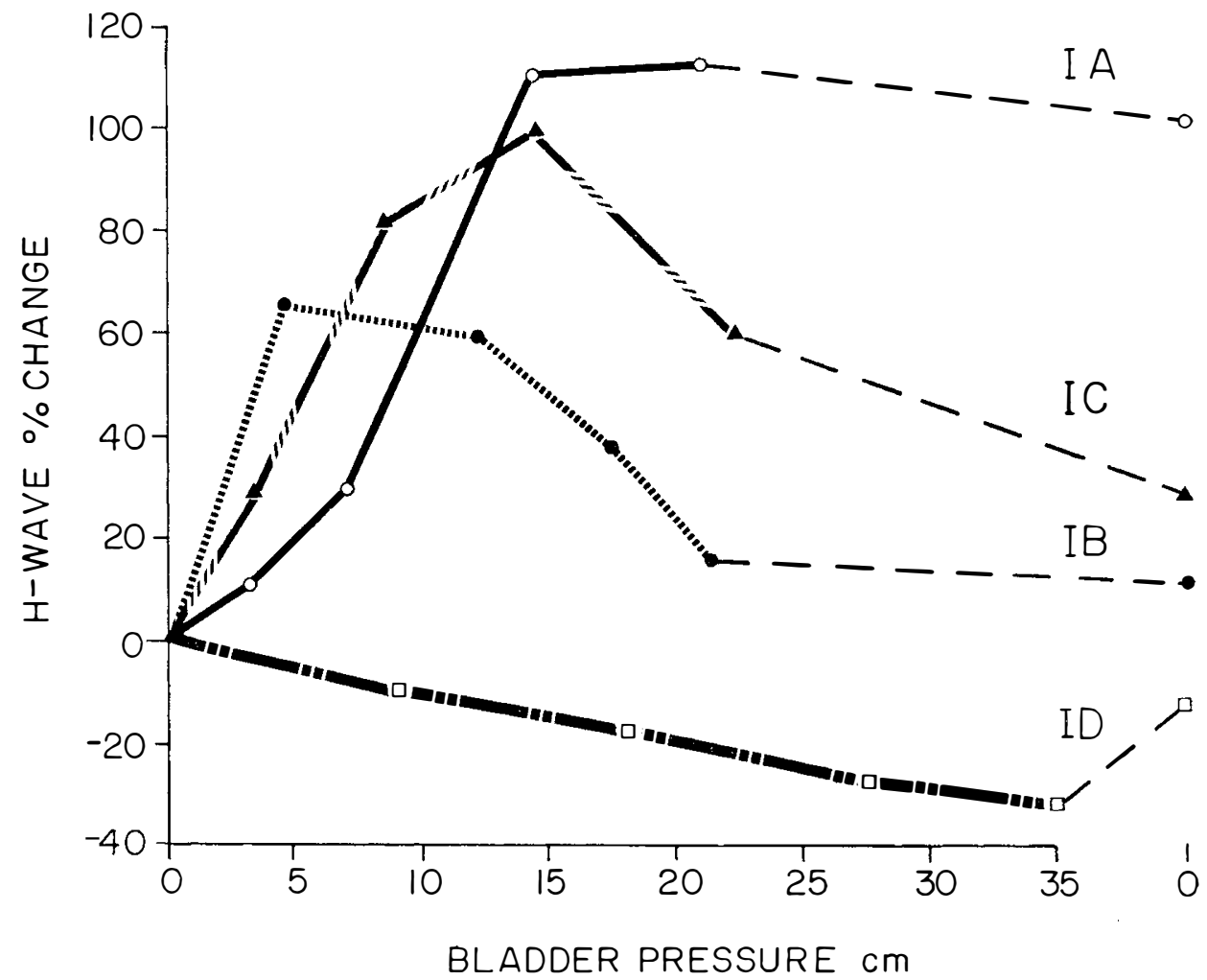

FIG. 2

The changes in $\mathrm{H}$-wave amplitude associated with increasing bladder pressure are shown for the 29 patients in Group I. Curve IA represents those patients with lesions from $\mathrm{C}_{5}$ to $\mathrm{C} 8$; Curve IB, TI-T5; and IC, T6-T8. Curve ID includes those five patients with lesions between $T_{I}$ and $T_{5}$ who had negative responses.

Bladder Characteristics. The five patients who showed a decreased H-wave amplitude in this group all had lesions between $\mathrm{T}_{\mathrm{I}}$ and $\mathrm{T}_{5}$. These patients (Curve ID, fig. 2) were separated from the other eight patients who had spinal cord lesions at this level (Curve IB, fig. 2) on the basis of a significant difference in the characteristics of their bladder function; namely, an increased pressure induced by a given volume of urine. These parameters were observed for each subject at the 40-minute interval and the pressure/volume ratio determined. ${ }^{2}$

\section{Group II}

Rate of Bladder Filling. Five of the patients in Group I with lesions between $\mathrm{T}_{\mathrm{I}}$ and $\mathrm{T} 5$ who showed a positive $\mathrm{H}$-wave response were further analysed with regard to the effect of rate of filling of the bladder upon the magnitude of the $\mathrm{H}$ wave response. The results described above in which measurements were made every Io minutes were compared with a second series of experiments during which the bladder was distended more rapidly and observations were made every 3

2 The average pressure/volume ratio obtained for Group IB was $0.17 \pm 0.026$ while that for Group ID was $0.30 \pm 0.035$. This difference was statistically significant ( $P$ value $<0.01)$. 
minutes. These results are shown in Figure 3a. It can be noted that the average response of these five patients when bladders were allowed to fill slowly (Group IIA) was similar to that previously seen when the responses of all eight patients were averaged. When the bladder was distended more rapidly, however, the $\mathrm{H}$-wave was diminished in all three measurements (Group IIB) until the bladder was emptied, when the amplitude of the response returned toward the control value.

Figure $3 \mathrm{~b}$ shows the changes in systolic blood pressure during the two series
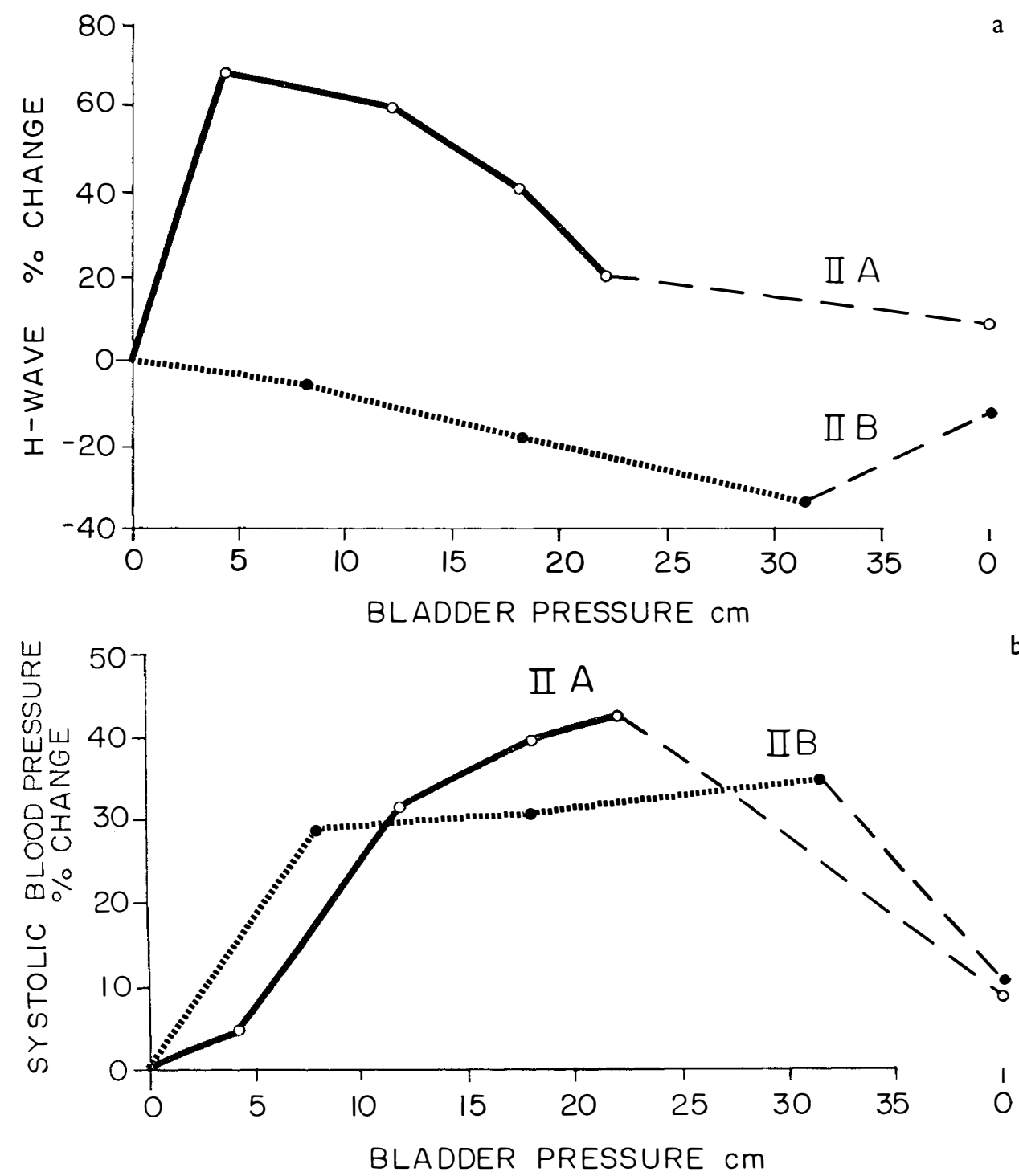

FIG. 3

a, Changes in the amplitude of the $\mathrm{H}$-wave for patients in Group II are plotted against changes in the bladder pressure. Curve IIA represents a 50-minute observation period with Io minutes between measurements. Curve IIB represents the same patients over a I2minute period with observations every 3 minutes. b, Changes in systolic blood pressure are plotted against changes in bladder pressure in the same experiments as described in a. 
of experiments. Curve IIA shows the increase in blood pressure observed during the 40-minute test period with the greatest increase observed between I0 and 20 minutes. When compared to Curve IIA (fig. 3a) it can be noted that the maximum $\mathrm{H}$-wave response occurred at the Io-minute interval and decreased thereafter. With more rapid filling of the bladder the greatest single increment of increased systolic blood pressure occurred during the first observation period (Curve IIB). Again, when compared to Curve IIB in Figure 3a it can be seen that the H-wave was diminishing in amplitude during the same time interval. The differences in the blood pressure values obtained were not statistically significant nor were the differences in bladder pressures at which time the maximum blood pressure increases were noted. However, there was a perfect correlation between the period during which the greatest change in blood pressure occurred and the period when the $\mathrm{H}$-wave response was first noted to decrease (either below the control value or returning toward normal after reaching its maximum value). This relationship was true not only for the average values as seen in Figure 3 but also for each individual subject.

\section{Group III}

Elapsed Time Following Injury. In these additional six patients the H-wave response to bladder distention was measured serially beginning 5 to 7 weeks after injury. The average results in these patients are shown in Figure 4a. In Curve IIIA, which represents those measurements made between the 5 th and 7 th weeks after injury the maximum $\mathrm{H}$-wave response is seen at the time of maximum bladder pressure. In contrast, when measurements were made 17 to I9 weeks following injury (Curve IIIC) the maximum $\mathrm{H}$-wave was obtained at the end of the first Io-minute test interval. The values for measurements made at the II- to I3-week interval fell between the other two series of observations (Curve IIIB). The difference between the maximum $\mathrm{H}$-wave amplitude noted in Groups IIIA and IIIC (Table I) were significant $(P$ value $<0.0 I) .{ }^{3}$ Similarly the differences in the bladder pressure at which the maximum $\mathrm{H}$-wave amplitude change were observed for Groups IIIA and IIIC were significant at the 0.0 I level. ${ }^{4}$ The change in bladder characteristics for these patients at the three different levels were observed (Table I) and the pressure/volume ratios calculated. ${ }^{5}$ The difference between Groups IIIA and IIIC was significant at the 0.05 level although comparisons with Group IIIB were not.

Figure $4 \mathrm{~b}$ shows the change in systolic blood pressure during each of the three series of experimental observations. Curves IIIB and IIIC indicate that the greatest single increment of change in the arterial pressure occurred in the interval following the manifestation of the maximum $\mathrm{H}$-wave response. This correlation was noted for each individual subject as well as for the average responses. This relationship cannot be determined for Group IIIA since the maximum H-wave response was noted at the last observation interval and the rise in arterial blood pressure up to that point was not significant.

\section{Discussion}

It is apparent from these experiments that certain characteristics of the $\mathrm{H}$-wave response can be significantly influenced by distension of the urinary bladder

3 Comparisons made between Group IIIB and Groups IIIA and IIIC were significant at the 0.05 level only.

4 Comparisons with Group IIIB were less significant ( $P$ value $<0.05$ ).

5 Pressure/volume ratios: IIIA, $0.15 \pm 0.022$; IIIB, $0.17 \pm 0.024$; and IIIC, $0.021 \pm 0.029$ 

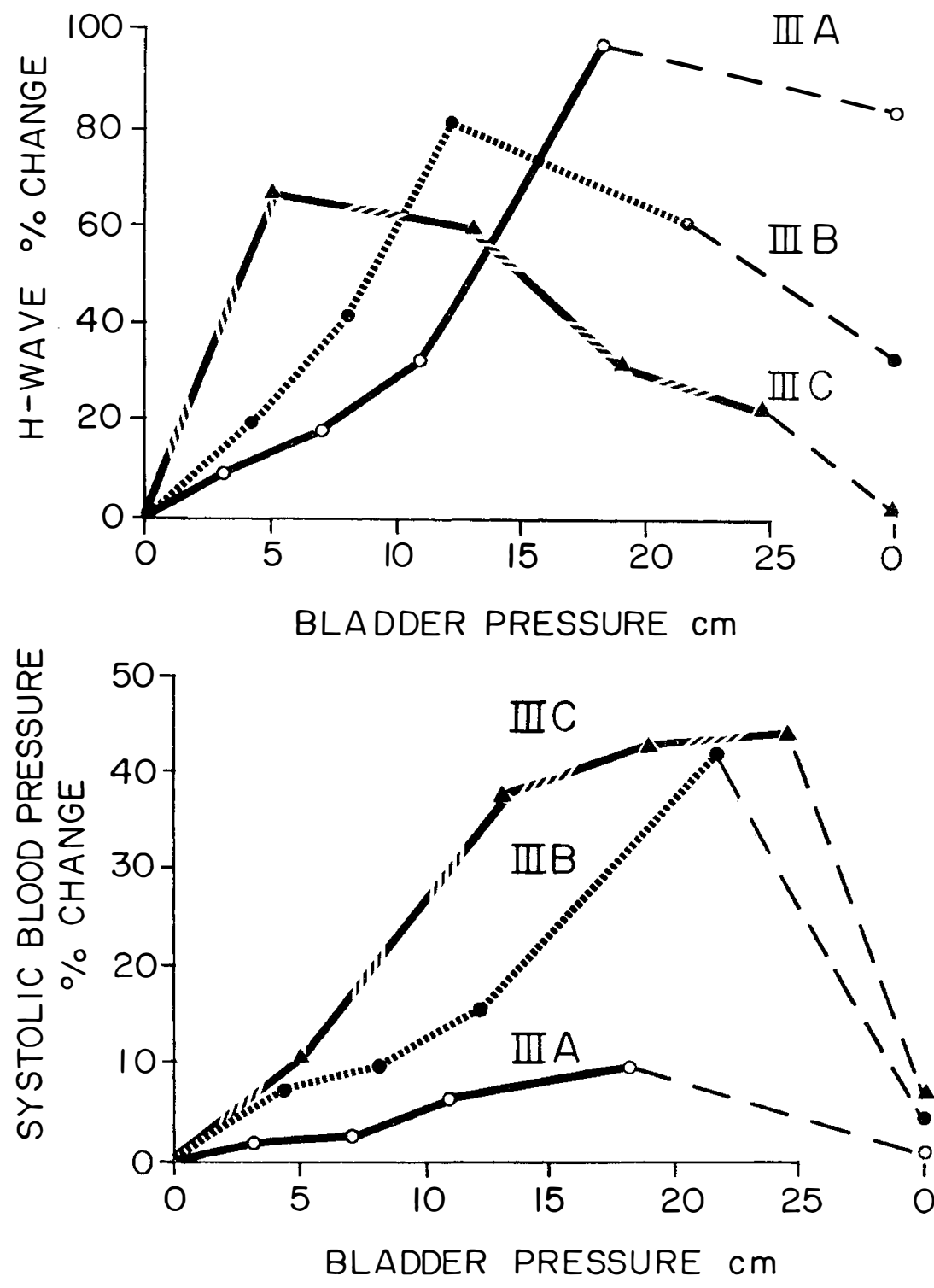

FIG. 4

a, Changes in the $\mathrm{H}$-wave amplitude for patients in Group III are plotted against changes in bladder pressure. The same six patients are examined at three different intervals: IIIA, 5 to 7 weeks; IIIB, II to I3 weeks; IIIC, I 7 to I 9 weeks. b, Changes in the systolic blood pressure are shown which correspond to the same experiments described in a.

in spinal cord injured patients. However, the relationship between these two events is complex and interpretation of these data is limited by several variables which are difficult to control. The $\mathrm{H}$-wave itself is an electrical phenomenon which is thought to represent a monosynaptic reflex (Hoffman, I9I8; Hoffman, I934; Magladery \& McDougal, I950). It displays considerable variability and for this reason has been used more in past years for research investigation than as a 
diagnostic tool (Mathews, I970). In these experiments this was minimised by computing the average of a series of responses and then using the amount of change in the response during any series of observations for comparison rather than absolute values.

For the most part the variations in the $\mathrm{H}$-wave amplitude could be accounted for by the characteristics of the applied stimulus; that is, bladder distention. However, the relationship between the volume of fluid accumulated in the bladder and the intravesical pressure induced, is highly variable in spinal cord dysfunction and is influenced by a number of different factors. In these experiments it was elected to allow the bladder to fill spontaneously in all but a few patients. Although this had the advantage of being a more physiologic situation the volume of fluid contained in the bladder was unknown until the end of each experiemnt. Therefore only in that series where the fluid was instilled into the bladder to evaluate the

\section{TABLE I}

The maximum $\mathrm{H}$-wave response and the bladder pressure at which it occurred are tabulated for each group. The final bladder volume and pressure are also recorded.

The standard error for each group of measurements is indicated

Maximum $\mathrm{H}$-wave Bladder pressure (percentage change) at maximum $\mathrm{H}$-wave

$\begin{array}{cr}\text { Group I } & \\ \text { A } & \text { II } 2 \cdot 5 \pm 4 \cdot 76 \\ \text { B } & 65 \cdot 3 \pm 3 \cdot 57 \\ \text { C } & \text { IOO.2 } \pm 4 \cdot 52 \\ \text { D } & -31 \cdot 0 \pm 3.95\end{array}$

Group II

$\begin{array}{lr}\text { A } & 64 \cdot 8 \pm 5 \cdot 92 \\ \text { B } & -33 \cdot 1 \pm 3 \cdot 97\end{array}$

Group III
A
B
$\mathrm{C}$ $(\mathrm{cm})$

$$
\begin{array}{r}
21 \cdot 0 \pm 1 \cdot 66 \\
4.4 \pm 0.59 \\
14.6 \pm 1 \cdot 05 \\
34.9 \pm 2.42
\end{array}
$$

Final bladder volume

(cc)

$$
\begin{aligned}
& \text { I } 29 \pm 5 \cdot 58 \\
& \text { I } 24 \pm 5 \cdot 02 \\
& \text { II } 3 \pm 5 \cdot 10 \\
& \text { II } \pm 77 \cdot 79
\end{aligned}
$$

Final bladder pressure

(cm)

$$
\begin{array}{r}
4 \cdot 2 \pm I \cdot I 8 \\
3 I \cdot 4 \pm 2 \cdot 48
\end{array}
$$

$$
\text { I } 22 \pm 5 \cdot 0 \mathrm{I}
$$$$
236 \pm 0.97
$$

$2 \mathrm{I} \cdot 0 \pm \mathrm{I} \cdot 66$

$2 \mathrm{I} \cdot 6 \pm \mathrm{I} \cdot 7 \mathrm{I}$

$22 \cdot 8 \pm \mathrm{I} \cdot 90$

$34.9 \pm 2.42$

$$
\begin{array}{r}
I 8 \cdot I \pm I \cdot 5 I \\
I I \cdot 8 \pm I \cdot 98 \\
5 \cdot I \pm I \cdot 30
\end{array}
$$

$22 \cdot 0 \pm I \cdot 93$

$3 \mathrm{I} \cdot 4 \pm 2 \cdot 48$

$\mathrm{I} 8 \cdot \mathrm{I} \pm \mathrm{I} \cdot 8 \mathrm{I}$

$2 \mathrm{I} \cdot 4 \pm \mathrm{I} \cdot 97$

$24 \cdot 7 \pm 2 \cdot 17$

effect of the rate of filling could an approximate relationship be determined between volume and pressure during the course of the experiment. In any event there seemed to be little correlation between the absolute pressure and the magnitude of the $\mathrm{H}$-wave response at any given time. The one characteristic of the stimulus which appeared to exert the greatest influence was the rate of change in the intravesical pressure. This in turn was influenced by two major factors-the rate of filling of the bladder and the resistance of tone of the bladder wall.

The effect of the rate of filling was clearly demonstrated in Group II when the same five patients were studied twice; once with bladder distention over a 40minute period, and again over a 9-minute interval. The $\mathrm{H}$-wave response in these two series was in opposite directions. The importance of the second factor which may determine the rate of increased intravesical pressure, namely the resistance of the bladder wall, is well demonstrated by the results in Group I and to a lesser extent in Group III. In Group I there were five patients who had bladder characteristics which were significantly different than the rest of the group. In these patients the tone was unusually high, thus pressure built up more rapidly. 
Although the same trend can be seen in the patients in Group III who were observed serially on three different occasions, the differences were not as great.

Although these variations in the characteristics of bladder function could account for most of the findings in this study there remain some unexplained differences in the $\mathrm{H}$-wave response when results at different levels of spinal cord injury are compared. However, since individuals within each group qualitatively showed the same type of response it would appear that these variations are significant, and may represent differences in the overall balance of suprasegmental facilitatory and inhibitory influences.

These data suggest that up to a point a visceral stimulus will facilitate motor excitability to incoming stimuli. When the intensity of the stimulus reaches a certain point, however, this facilitation is reversed. If the stimulus is great enough at the outset, the $\mathrm{H}$-wave response may be depressed throughout. These findings are consistent with animal studies which have shown that there may be differences in both somatic reflex activity and recorded electrical activity in spinal roots depending upon the degree of bladder distention (Dusser de Barenne \& Ward, I937; Abdullah \& Eldred, I959; Evans \& McPherson, I959; Evans, I963; McPherson, I966).

The possible correlation between arterial blood pressure and $\mathrm{H}$-wave changes are of considerable interest, although its significance is inconclusive. It appears, however, that the greatest change in blood pressure occurs during that period when the rate of change of bladder pressure is such that facilitation of the $\mathrm{H}$-wave response is reversed. Presumably it is at that point that a mass spinal reflex is evoked which includes elevation of blood pressure and during which the response to further incoming somatic stimuli is no longer maximally facilitated.

\section{SUMMARY}

Changes in the amplitude of the H-wave reflex associated with distention of the urinary bladder have been studied in 35 patients with functionally complete lesions of the spinal cord between $\mathrm{C}_{5}$ and Tro. Under the conditions of these experiments 30 of these patients showed an increased amplitude of the H-wave at some point during bladder distention while 5 patients had a decreased H-wave response throughout the entire period of increased intravesical pressure. Several factors appeared to influence the timing and extent of the response including the characteristics of the bladder itself, the level of spinal cord injury and the time elapsed since injury. It was concluded that the most important single factor in determining the characteristics of the $\mathrm{H}$-wave response was the rate of change of bladder pressure rather than any single measurement of absolute pressure. Increased systolic blood pressure was noted during the course of these experiments and the greatest single increment of change was invariably found in that observation period following the maximum $\mathrm{H}$-wave response. It was felt that this point may represent the onset of a mass spinal reflex during which the $\mathrm{H}$-wave response to further incoming somatic stimuli is no longer maximally facilitated.

\section{RÉSUMÉ}

Les changements dans l'amplitude de l'ondulation-H réflexe associée avec la distension de la vésicule urinaire a été etudié dans 35 clients avec les lésions fonctionnelment complet de la moelle épinière entre $\mathrm{C}_{5}$ et $\mathrm{T}_{\mathrm{O}}$. Sous les états de ces expériences 30 de ces clients ont montrés l'amplitude augmentée de l'ondulation-H a quelque temps pendant la distension de la vésicule urinaire et 5 clients ont montrés l'amplitude diminuée par tout le temps de la 
intravesiculaire tension augmentée. Plusieurs d'éléments paraît d'influencer le temps et le degré de la réponse, comprenant les traits caracteristiques de la vésicule urinaire, le degré de la blessure à la moelle épinière, et le temps qui ont passé depuis la blessure. On a jugè que l'élément la plus importante en décider les traits caracteristiques de l'ondulation- $\mathrm{H}$ réponse a été la vitesse des variations dans la tension de la vésicule urinaire plus que quelque mesurage simple de la tension absolue. On a remarqué une augmentation de la tension du sang systolique pendant les expériences et la plus grande augmentation simple s'est trouvée uniformément dans le period observé suivant la réponse maximum de l'ondulation- $\mathrm{H}$. On a decidé que cet point, peut-être, montre le début d'une réponse masif spinal pendant que la réponse de l'ondulation- $\mathrm{H}$ a nouveaux stimulants somatiques n'est plus utilisé au maximum.

\section{ZUSAMMENFASSUNG}

Bei 35 Patienten mit funktionellen vollständigen Verletzungen des Rückenmarks zwischen $\mathrm{C}_{5}$ und TIO wurden Veränderungen im Umfang des $\mathrm{H}$-Wellenreflexes beobachtet. Unter den Bedingungen dieser Experimente zeigten 30 Patienten einen zunehmenden Umfang der $\mathrm{H}$-welle im Laufe der Blasenausdehnung, dagegen zeigten 5 Patienten während der Dauer des zunehmenden Intrasikulären Drucks eine abnehmende H-Wellenreaktion. Verschiedene Faktoren beinflussten den Zeitpunkt und den Umfang der Reaktion, die Chrakteristika der Blase selbst, sowie die Schwere der Rückenmarksverletzung und der Zeitpunkt der Veletzung. Es wurde beschlossen, dass der ausschlaggebende Faktor im Feststellen der Characteristika der $\mathrm{H}$-Wellenreaktion das Veränderungsverhältnis des Blasendruckes war, anstatt einzelner Berechnung von absolutem Druck. Zunehmender systolischer Blutdruck wurde im Laufe dieser Experimente beobachtet und der grösste Zuwachs wurde in diesen Experimenten im Anschluss an die maximum H-Wellenreaktion festegstellt. Möglicherweise könnte dies als der Ansatzpunkt für eine massive Rückenmarksreaktion angenommen werden, während der die $\mathrm{H}$-Wellenreaktion zu weiteren somatischen Stimuli nicht mehr maximal gefördert werden.

\section{REFERENCES}

Abdullah, A. \& Eldred, E. (1959). Activity in gamma efferent circuits induced by distension of the bladder. F. Neuropath. 18, 590-596.

Dusser De BARENNE, J. C. \& WARD, A. A., JR. (1937). Reflex inhibition of knee jerk from intestinal organs. Am. F. Physiol. 120, 340-344.

Evans, M. H. \& McPherson, A. (I959). The effects of distention of the bladder on somatic reflexes in the cat. F. Physiol. I46, $438-458$.

Evans, M. H. (1963). Alterations in activity of gamma efferents during distension of the bladder in the cat. F. Physiol. 165, 358-367.

HoffMAN, P. (I9I8). Über die Bezidhungen der sehen Reflexe zur wilkürlichen Bewegung and zun Tonus. Z. Biol. 68, 351-370.

Hoffman, P. (1934). Die physiologischen Eigenschaften der Eigenreflex. Ergebn. Physiol. 36, I5-180.

IshikaWA, K., OTt, K., Porter, R. W. and Stuart, D. (I965). Low frequency depression of the H-wave in normal and spinal man, Exp. Neurol. 15, I40-I56.

MAgLAdERY, J. W. \& MCDougal, D. B., JR. (1950). Electrophysiological studies of nerve and reflex activity in normal man. I. Identification of certain reflexes in the electromyogram and the conduction velocity of peripheral nerve fibers. Bull. Fohn Hopkins Hosp. 86, 265-290.

Mathews, W. B. (I970). The clinical implication of the H-reflex and other electrically induced reflexes. In Williams, D. (ed.): Modern Trends in Neurology, Vol. 5. London: Butterworths, pp. 24I-253.

MCPherson, A. (1966). Vesico-somatic reflexes in the chronic spinal cat. F. Physiol. 185, I97-204. 